\title{
Optimization of the homogenization and hot isostatic pressing heat treatments of a fourth generation single crystal superalloy
}

\author{
Pierre Caron ${ }^{\mathrm{a}}$ and Catherine Ramusat \\ Onera, The French Aerospace Lab, 92322 Châtillon Cedex, France
}

\begin{abstract}
Various solution heat treatment sequences including a hot isostatic pressing step were tested on the MC-NG fourth generation single crystal superalloy with the aim to minimize the total duration of the treatment while obtaining a satisfactory level of microstructural homogeneity and low amount and size of pores. A procedure including the HIP step after full solutioning of the material allows to avoid reopening of the pores but needs a short post-HIP heat treatment followed by air quenching to get the desired $\gamma^{\prime}$ precipitate size. The total duration of the solution heat treatment has been reduced from 18 to 6 hours as compared with the previous standard procedure.
\end{abstract}

\section{Introduction}

Single crystal (SC) blades and vanes made of highly alloyed $\gamma-\mathrm{Ni} / \gamma^{\prime}-\mathrm{Ni}_{3} \mathrm{Al}$ type nickel-based superalloys are today widely used in the high-pressure section of the gas turbine of aircraft and helicopter engines, and of the most efficient industrial gas turbine engines for power generation. These components are produced by investment casting in directional solidification (DS) Bridgman furnaces using grain selector or seeding techniques. The conditions of thermal gradient and withdrawal rate used in these industrial furnaces lead to dendritic microstructures. During directional solidification, $\gamma$-phase dendrites form first, and then the last liquid solidifies through a eutectic reaction resulting in coarse interdendritic $\gamma / \gamma^{\prime}$ pools. During subsequent cooling in the solid state submicron size $\gamma^{\prime}$ particles precipitate within the primary $\gamma$ dendrites. Moreover, pores form into the interdendritic region due to solidification shrinkage.

Since the seminal work of Jackson et al. on the DS Mar-M200 + Hf superalloy [1] it is well-recognized that the creep strength of such dendritic alloys increases with the volume fraction of $\gamma^{\prime}$ precipitates with a size less than $0.5 \mu \mathrm{m}$. In order to benefit from the whole strengthening potential of the $\gamma^{\prime}$ phase it is therefore of prime importance to eliminate the coarse $\gamma / \gamma^{\prime}$ pools thanks to a solution heat treatment applied above the solvus temperature of the $\gamma^{\prime}$ phase. All of the $\gamma^{\prime}$-former alloying element atoms such as $\mathrm{Al}, \mathrm{Ti}$, Ta and $\mathrm{Nb}$ will therefore participate in the formation of fine $\gamma^{\prime}$ precipitates during cooling following the solutioning heat treatment. In conventionally cast (CC) equiaxed or columnar grained DS superalloys, relatively high levels of grain boundary strengthening elements as $\mathrm{C}, \mathrm{B}, \mathrm{Hf}$, and $\mathrm{Zr}$ lower the solidus temperature below the $\gamma^{\prime}$ solvus temperature that precludes total solutioning

${ }^{\mathrm{a}}$ Corresponding author: pierre.caron@onera.fr of the $\gamma / \gamma^{\prime}$ eutectic and coarse $\gamma^{\prime}$ precipitates without incipient melting. On the contrary, removal or tight control of these minor elements in SC superalloys allow complete solutioning of all the $\gamma^{\prime}$ particles as the solidus temperature can exceed the $\gamma^{\prime}$ solvus temperature. In first generation SC superalloys, the relatively low amount of $\gamma / \gamma^{\prime}$ eutectic can be totally dissolved by applying a single step solution heat treatment for a duration of about 3 hours, as for the MC2 alloy [2]. In the following generations of $\mathrm{Ni}$ based SC superalloys, the amount and size of $\gamma / \gamma^{\prime}$ eutectic pools increase with the levels of alloying elements that renders more and more difficult to fully dissolve the massive interdendritic $\gamma^{\prime}$ particles. Successive heat treatment steps with increasing temperatures are thus needed to progressively homogenize the dendrites, to increase the solidus temperature and to avoid localized incipient melting. That results in significant increase of the total heat treatment duration, and consequently of the alloy processing cost. As an example, the third generation CMSX-10 SC alloy needs a ten-step solution heat treatment procedure with a cumulative duration of 45 hours [3].

Casting pores in the SC Ni-based superalloys are the main structural defects where cracks initiate under mechanical loading. In particular, the volume fraction and above all the size of the pores strongly influence the life of SC superalloys under cyclic loading. It has been widely demonstrated that reducing the pore size has a dramatic beneficial effect on high cycle fatigue (HCF) and low cycle fatigue (LCF) life of such alloys. Reduction of the pore size can be obtained by using DS conditions leading to finer dendrites, i.e. high temperature gradient or withdrawal rate. A high temperature gradient, stable during the entire solidification process, is however difficult to maintain in large industrial Bridgman furnaces, excepted by using liquid metal cooling technique but to a limited extent. 
Another efficient way to significantly reduce porosity is to apply a hot isostatic pressing (HIP) treatment to the cast component. For instance, both processes have been shown to be very effective in increasing the LCF and especially the HCF behaviour of the CMSX-2 SC superalloy [4].

The purpose of the present work is to identify an optimized heat treatment procedure for the fourth generation MC-NG SC superalloy, combining a solution heat treatment and a HIP treatment as efficient and as short as possible.

\section{Experimental}

The alloy used in the present work is the fourth generation MC-NG superalloy (4wt.\% Cr, $1 \mathrm{Mo}, 5 \mathrm{~W}, 4 \mathrm{Re}, 4 \mathrm{Ru}$, $6 \mathrm{Al}, 0.5 \mathrm{Ti}, 5 \mathrm{Ta}, 0.1 \mathrm{Hf}, 0.1 \mathrm{Si}$ and $\mathrm{Ni}$ as balance) developed by ONERA for high temperature SC turbine blade applications [5]. $\langle 001\rangle$-oriented single crystal bars produced by Snecma using an industrial Bridgman furnace were provided in the as-cast conditions.

Alloy samples sectioned from the middle part of the bars normal to their growth axis were given various solution heat treatment procedures described in Table 1. All the heat treatments were performed in a tubular laboratory furnace under flow of argon. The alumina crucible containing the sample is introduced in the furnace pre-heated at $1300^{\circ} \mathrm{C}$. After a hold for 10 minutes at $1300^{\circ} \mathrm{C}$, the temperature is increased to $1310^{\circ} \mathrm{C}$ in 20 minutes. At this time, the solution heat treatment is considered to start.

The 16-hour two-step standard solution heat treatment (SSHT) was defined and used during the alloy development phase and needed to be optimized in term of total duration. A first modification was to increase the heating rate between the two heat treatment holds at $1310^{\circ} \mathrm{C}$ and $1340^{\circ} \mathrm{C}$ (MSHT 1). A second modification was to suppress the initial hold at $1310^{\circ} \mathrm{C}$ and to increase directly the temperature from $1310^{\circ} \mathrm{C}$ to $1340{ }^{\circ} \mathrm{C}$ at a rate of 10 or $20^{\circ} \mathrm{C} \cdot \mathrm{min}^{-1}$, followed by a hold for 1,2 or 3 hours at $1340^{\circ} \mathrm{C}$. In all cases, the samples were finally air quenched (AQ) by withdrawing rapidly the crucible out of the furnace and pouring the sample in a stainless steel tank. The $\gamma^{\prime}$ precipitate size observed in as-quenched samples is typical of a quenching rate in the $200-300^{\circ} \mathrm{C} \cdot \mathrm{min}^{-1}$ range, and comparable to that resulting from gas fan quenching used during industrial heat treatment procedures.

Some solution heat treatment procedures including a hot isostatic pressing (HIP) step have been tested on as-cast MC-NG samples (Table 2). The conditions of the HIP were the same for the three procedures. In the standard procedure (SP), HIP is performed before the standard solution heat treatment where the duration of the heat treatment hold at $1310^{\circ} \mathrm{C}$ is reduced to 2 hours. The HIP step is performed after the SSHT or MSHT 6 solution heat treatment in the MP1 and MP2 modified procedures, respectively. In both cases, a short additional heat treatment at $1340^{\circ} \mathrm{C}$ for 30 minutes, followed by air quenching, is applied after the HIP step.

Microstructural assessments were performed on the as-cast and heat treated samples by means of light microscopy (LM) and scanning electron microscopy (SEM) in order to check the dendritic and $\gamma / \gamma^{\prime}$
Table 1. Solution heat treatment procedures tested in this study (AQ: air quench).

\begin{tabular}{|c|c|}
\hline $\begin{array}{l}\text { Standard solution heat } \\
\text { treatment (SSHT) }\end{array}$ & $\begin{array}{l}1310^{\circ} \mathrm{C} / 3 \mathrm{~h} \rightarrow \text { heat- } \\
\text { ing ramp at } 3^{\circ} \mathrm{C} \cdot \mathrm{h}^{-1} \rightarrow \\
1340^{\circ} \mathrm{C} / 3 \mathrm{~h} / \mathrm{AQ}\end{array}$ \\
\hline $\begin{array}{l}\text { Modified solution heat } \\
\text { treatment } 1 \text { (MSHT 1) }\end{array}$ & $\begin{array}{l}1310^{\circ} \mathrm{C} / 3 \mathrm{~h} \rightarrow \text { heating } \\
\text { ramp at } 10^{\circ} \mathrm{C} \cdot \mathrm{h}^{-1} \rightarrow \\
1340^{\circ} \mathrm{C} / 3 \mathrm{~h} / \mathrm{AQ}\end{array}$ \\
\hline $\begin{array}{l}\text { Modified solution heat } \\
\text { treatment } 2 \text { (MSHT 2) }\end{array}$ & $\begin{array}{l}\text { Heating ramp rat } \\
10^{\circ} \mathrm{C} \cdot \mathrm{h}^{-1} \\
1310^{\circ} \mathrm{C} \text { to } 1340^{\circ} \mathrm{C} \\
\rightarrow 1340^{\circ} \mathrm{C} / 3 \mathrm{~h} / \mathrm{AQ}\end{array}$ \\
\hline $\begin{array}{l}\text { Modified solution heat } \\
\text { treatment } 3 \text { (MSHT 3) }\end{array}$ & $\begin{array}{l}\text { Heating ramp rat } \\
20^{\circ} \mathrm{C} \cdot \mathrm{h}^{-1} \text { at } \\
1310^{\circ} \mathrm{C} \text { to } 1340^{\circ} \mathrm{C} \\
\rightarrow 1340^{\circ} \mathrm{C} / 1 \mathrm{~h} / \mathrm{AQ} \\
\end{array}$ \\
\hline $\begin{array}{l}\text { Modified solution heat } \\
\text { treatment } 4 \text { (MSHT 4) }\end{array}$ & $\begin{array}{l}\text { Heating ramp rat } \\
10^{\circ} \mathrm{C} \cdot \mathrm{h}^{-1} \text { arom } \\
1310^{\circ} \mathrm{C} \text { to } 1340^{\circ} \mathrm{C} \\
\rightarrow 1340^{\circ} \mathrm{C} / 1 \mathrm{~h} / \mathrm{AQ}\end{array}$ \\
\hline $\begin{array}{l}\text { Modified solution heat } \\
\text { treatment } 5 \text { (MSHT 5) }\end{array}$ & $\begin{array}{l}\text { Heating ramp rat } \\
20^{\circ} \mathrm{C} \cdot \mathrm{h}^{-1} \text { arom } \\
1310^{\circ} \mathrm{C} \text { to } 1340^{\circ} \mathrm{C} \\
\rightarrow 1340^{\circ} \mathrm{C} / 3 \mathrm{~h} / \mathrm{AQ}\end{array}$ \\
\hline $\begin{array}{l}\text { Modified solution heat } \\
\text { treatment } 6 \text { (MSHT 6) }\end{array}$ & $\begin{array}{l}\text { Heating ramp rat } \\
20^{\circ} \mathrm{C} \cdot \mathrm{h}^{-1} \\
1310^{\circ} \mathrm{C} \text { to } 1340^{\circ} \mathrm{C} \\
\rightarrow 1340^{\circ} \mathrm{C} / 2 \mathrm{~h} / \mathrm{AQ}\end{array}$ \\
\hline
\end{tabular}

Table 2. Solution heat treatment procedures including a HIP step tested in this study (FQ: furnace cooling, AQ: air quench).

\begin{tabular}{|c|c|}
\hline $\begin{array}{l}\text { Standard procedure } \\
(\mathrm{SP})\end{array}$ & $\begin{array}{l}\mathrm{HIP} \text { at } 1310^{\circ} \mathrm{C} / 2 \mathrm{~h} / 140 \\
\mathrm{MPa} / \mathrm{FC}+1310^{\circ} \mathrm{C} / 2 \\
\mathrm{~h} \rightarrow \text { heating ramp at } \\
3^{\circ} \mathrm{C} \cdot \mathrm{h}^{-1} \rightarrow 1340^{\circ} \mathrm{C} / 3 \\
\mathrm{~h} / \mathrm{AQ}\end{array}$ \\
\hline $\begin{array}{l}\text { Modified procedure } 1 \\
\text { (MP 1) }\end{array}$ & $\begin{array}{l}1310^{\circ} \mathrm{C} / 3 \mathrm{~h} \rightarrow \text { heating } \\
\text { ramp at } 3^{\circ} \mathrm{C} \cdot \mathrm{h}^{-1} \rightarrow \\
1340^{\circ} \mathrm{C} / 3 \mathrm{~h} / \mathrm{AQ}+\mathrm{HIP} \\
\text { at } 1310^{\circ} \mathrm{C} / 2 \mathrm{~h} / 140 \\
\mathrm{MPa} / \mathrm{FC}+1340^{\circ} \mathrm{C} / 30 \\
\mathrm{~min} / \mathrm{AQ}\end{array}$ \\
\hline $\begin{array}{l}\text { Modified procedure } 2 \\
\text { (MP 2) }\end{array}$ & $\begin{array}{l}\text { Heating ramp rat } \\
20^{\circ} \mathrm{C} \cdot \mathrm{h}^{-1} \\
1310^{\circ} \mathrm{C} \text { to } 1340^{\circ} \mathrm{C} \\
\rightarrow 1340^{\circ} \mathrm{C} / 2 \mathrm{~h} / \mathrm{AQ}+ \\
\mathrm{HIP} \text { at } 1340^{\circ} \mathrm{C} / 2 \mathrm{~h} / 140 \\
\mathrm{MPa} / \mathrm{FC}+1310^{\circ} \mathrm{C} / 30 \\
\min / \mathrm{AQ}\end{array}$ \\
\hline
\end{tabular}

microstructures and to quantify the microporosity. In order to evaluate the level of solutioning of the $\gamma / \gamma^{\prime}$ eutectic pools and to reveal the $\gamma^{\prime}$ precipitates, the samples were mechanically polished then chemically etched. Imaging of the microporosity was performed using light microscopy on as-polished samples. The APHELION ${ }^{\mathrm{TM}}$ image processing and analysis software was used to obtain binary images using a thresholding procedure and for quantitative analysis of these binary images. 

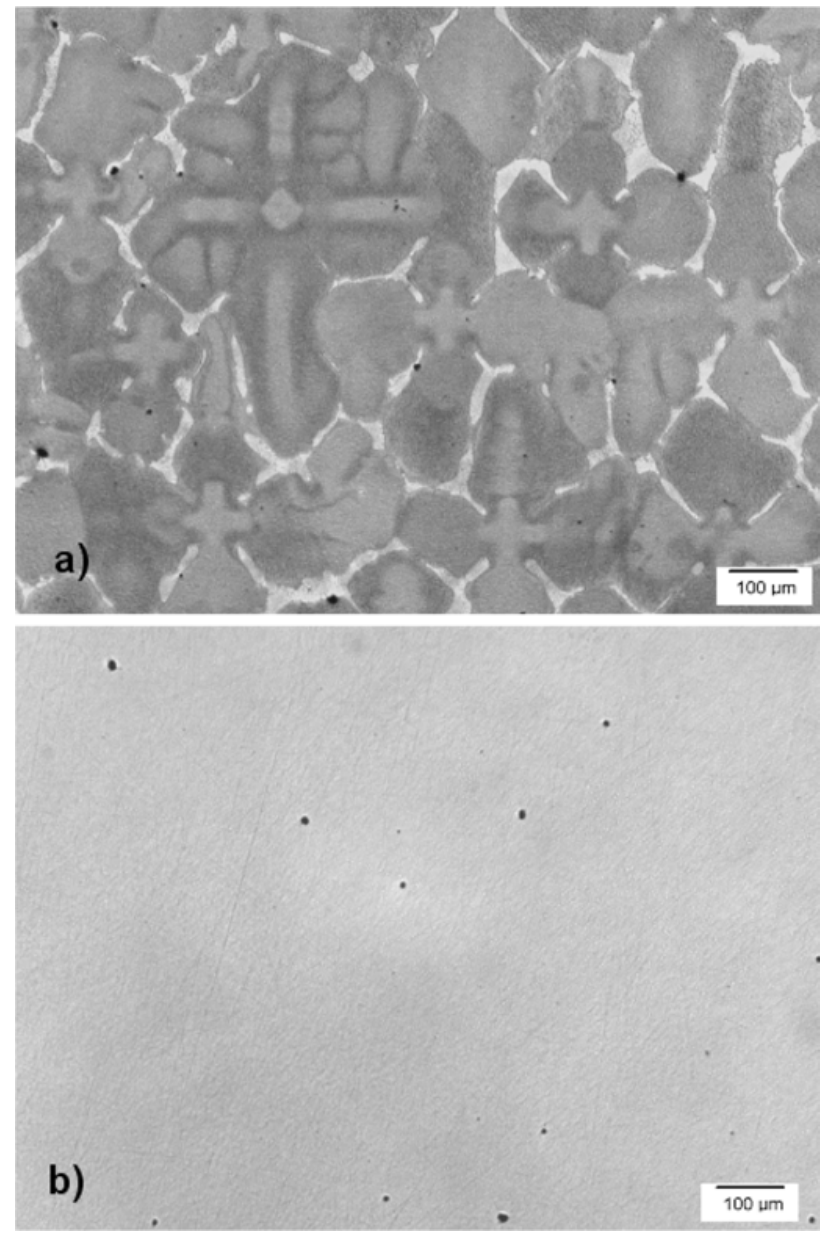

Figure 1. Typical as-cast microstructures of the MC-NG alloy (light microscopy; section normal to the $\langle 001\rangle$ growth axis): a) etched sample; b) polished sample.

The porosity was characterized by its area fraction $\mathrm{F}_{A}(\%)$, the number of pores by area unit $\mathrm{N}_{A}\left(\mathrm{~mm}^{-2}\right)$ and the average pore size $\mathrm{D}(\mu \mathrm{m})$. The pore size of a pore is defined as the diameter of the disk having the same area. This parameter does not give any information about the shape of the pore which can be quite tortuous in case of large shrinkage porosity, or about the largest dimension of a pore, but comparison of the values of D obtained for different heat treatment procedures gives a good indication of their respective effects. For each sample, average values were computed from measurements performed on sixteen $1 \mathrm{~mm}^{2}$ contiguous fields recorded with the light microscope.

\section{Results and discussion}

\subsection{Optimisation of the solution heat treatment}

Typical as-cast microstructures at the dendrite scale of the MC-NG SC bars are illustrated in Fig. 1. The standard solution heat treatment procedure (SSHT) eliminates all the interdendritic $\gamma / \gamma^{\prime}$ eutectic pools (Fig. 2a). Chemical etching reveals residual chemical dendritic segregations. Microporosity appears more developed than in the as-cast
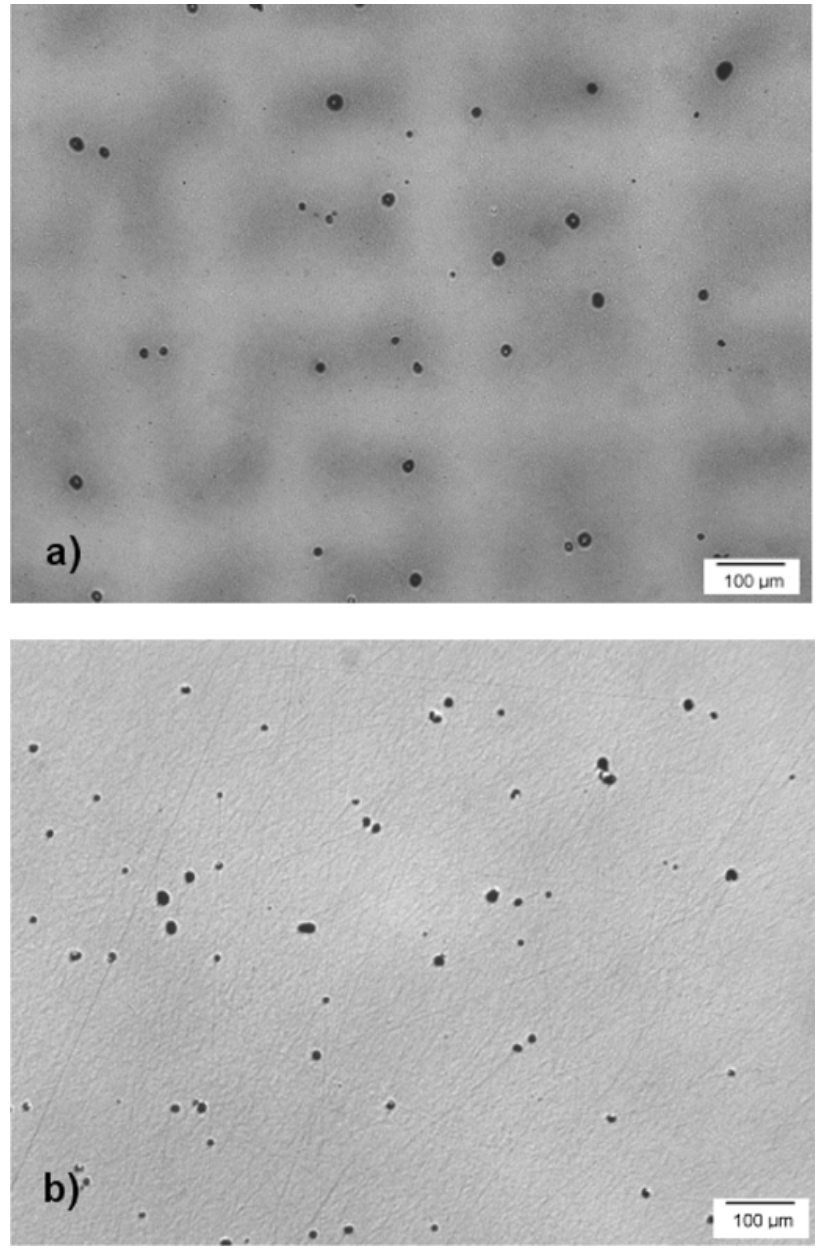

Figure 2. Typical SSHT microstructures of the MC-NG alloy (light microscopy; section normal to the $\langle 001\rangle$ growth axis): a) etched sample; b) polished sample.

alloy (Fig. 2b) as confirmed by the results of quantitative image analyses (Table 3).

The area fraction, density and size of the pores in the SSHT sample are significantly increased as compared with the as-cast material. Pore growth is assumed to result from Kirkendall-Frenkel effect leading to generation of vacancies due to imbalanced cross-diffusion of the alloying elements during the $\gamma^{\prime}$ supersolvus solution heat treatment [6]. Expansion of gaseous pore cannot also be excluded.

Microstructural assessments have been performed on samples submitted to the modified solution heat treatments in order to check the level of solutioning of the $\gamma / \gamma^{\prime}$ eutectic pools. Increasing the heating rate from $3{ }^{\circ} \mathrm{C} \cdot \mathrm{min}^{-1}$ to $10^{\circ} \mathrm{C} \cdot \mathrm{min}^{-1}$ between the two heat treatment holds at $1310^{\circ} \mathrm{C}$ and $1340^{\circ} \mathrm{C}$ (MSHT 1) reduces the total duration of the solution heat treatment from 16 to 9 hours but still allows to fully eliminate the $\gamma / \gamma^{\prime}$ eutectic phases. Suppressing the initial hold at $1310^{\circ} \mathrm{C}$ and using a heating rate of $10^{\circ} \mathrm{C} \cdot \mathrm{min}^{-1}$ to attain $1340^{\circ} \mathrm{C}$ (MSHT 2) reduces the total duration of the solution heat treatment to 6 hours and still leads to complete dissolution of the $\gamma / \gamma^{\prime}$ eutectic. In order to reduce the total duration of the solution heat 
Table 3. Characteristics of the microporosity in as-cast and solution heat treated MC-NG samples.

\begin{tabular}{|l|l|l|l|l|}
\hline \multicolumn{2}{|c|}{} & $\begin{array}{l}\mathrm{F}_{A}: \text { area } \\
\text { fraction } \\
(\%)\end{array}$ & $\begin{array}{l}\mathrm{N}_{A}: \\
\text { number } \\
\text { of pores per } \\
\mathrm{mm}^{2}\end{array}$ & $\begin{array}{l}\text { D: pore } \\
\text { size } \\
(\mu \mathrm{m})\end{array}$ \\
\hline \multirow{3}{*}{ As-cast } & Max. & 0.50 & 26 & 27 \\
\cline { 2 - 5 } & Average & $\mathbf{0 . 2 8}$ & $\mathbf{1 4}$ & $\mathbf{9}$ \\
\cline { 2 - 5 } & Min. & 0.14 & 9 & 3 \\
\hline \multirow{3}{*}{ SSHT } & Max. & 0.94 & 66 & 37 \\
\cline { 2 - 5 } & Average & $\mathbf{0 . 6 9}$ & $\mathbf{4 7}$ & $\mathbf{1 3}$ \\
\cline { 2 - 5 } & Min. & 0.42 & 37 & 3 \\
\hline \multirow{3}{*}{ MSHT 6 6 } & Max. & 0.89 & 85 & 34 \\
\cline { 2 - 5 } & Average & $\mathbf{0 . 5 9}$ & $\mathbf{6 6}$ & $\mathbf{1 0}$ \\
\cline { 2 - 5 } & Min. & 0.41 & 54 & 3 \\
\hline
\end{tabular}
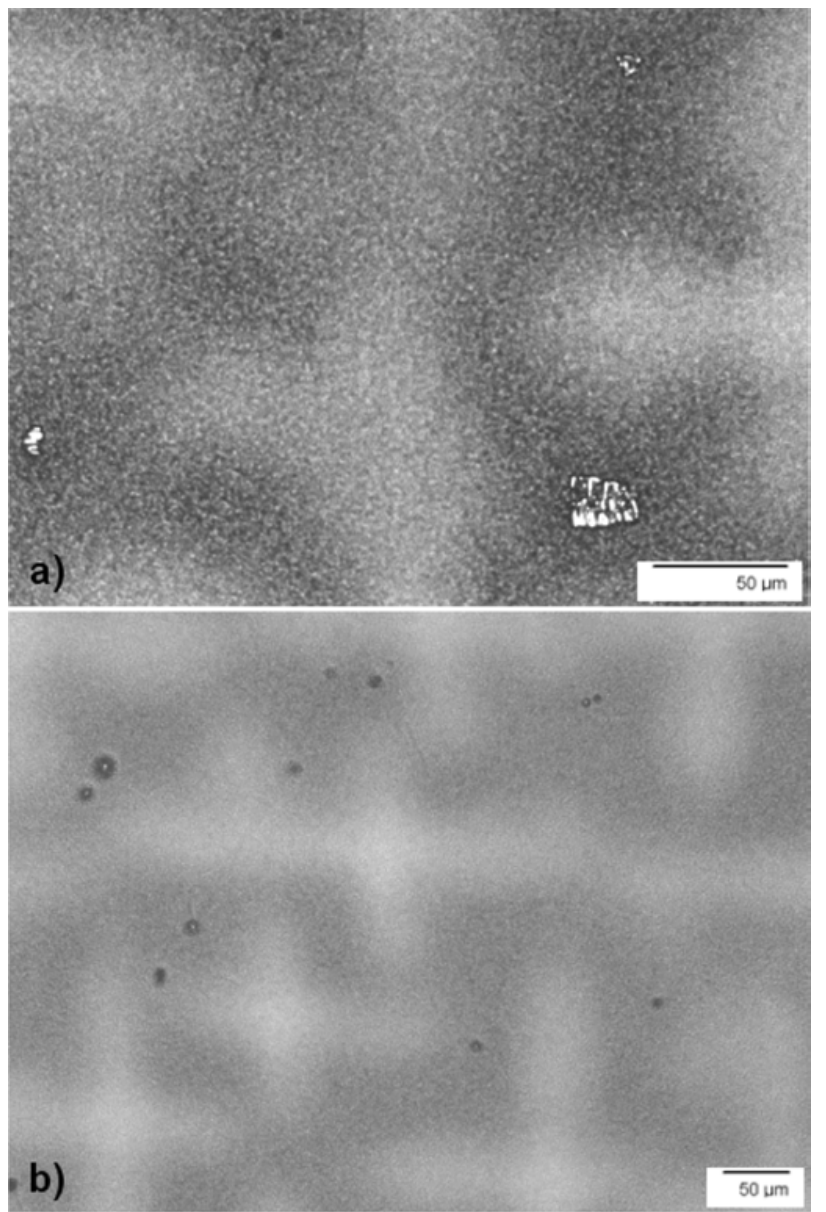

Figure 3. Typical MSHT microstructures of the MC-NG alloy (light microscopy; section normal to the $\langle 001\rangle$ growth axis; etched sample): a) MSHT 3; b) MSHT 6.

treatment to $2 \mathrm{~h} 30 \mathrm{~min}$, the MSHT 3 was then tried both by doubling the heating rate between $1310^{\circ} \mathrm{C}$ and $1340^{\circ} \mathrm{C}$ and by reducing to one hour the hold time at $1340^{\circ} \mathrm{C}$. Following this treatment, residual $\gamma / \gamma^{\prime}$ eutectic remains within some interdendritic areas (Fig. 3a). Going back to a heating rate of $10^{\circ} \mathrm{C} \cdot \mathrm{min}^{-1}$ while keeping a onehour hold time at $1340{ }^{\circ} \mathrm{C}$ (MSHT 4) is not enough to

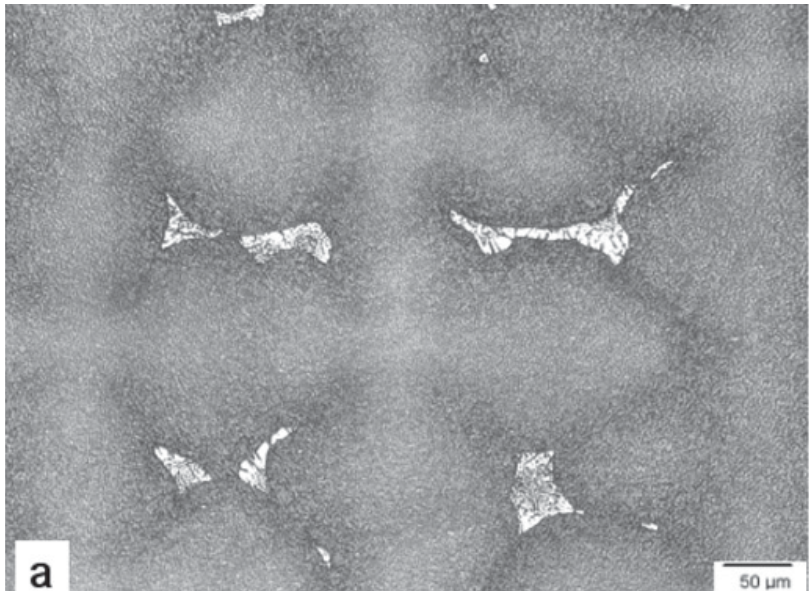

a

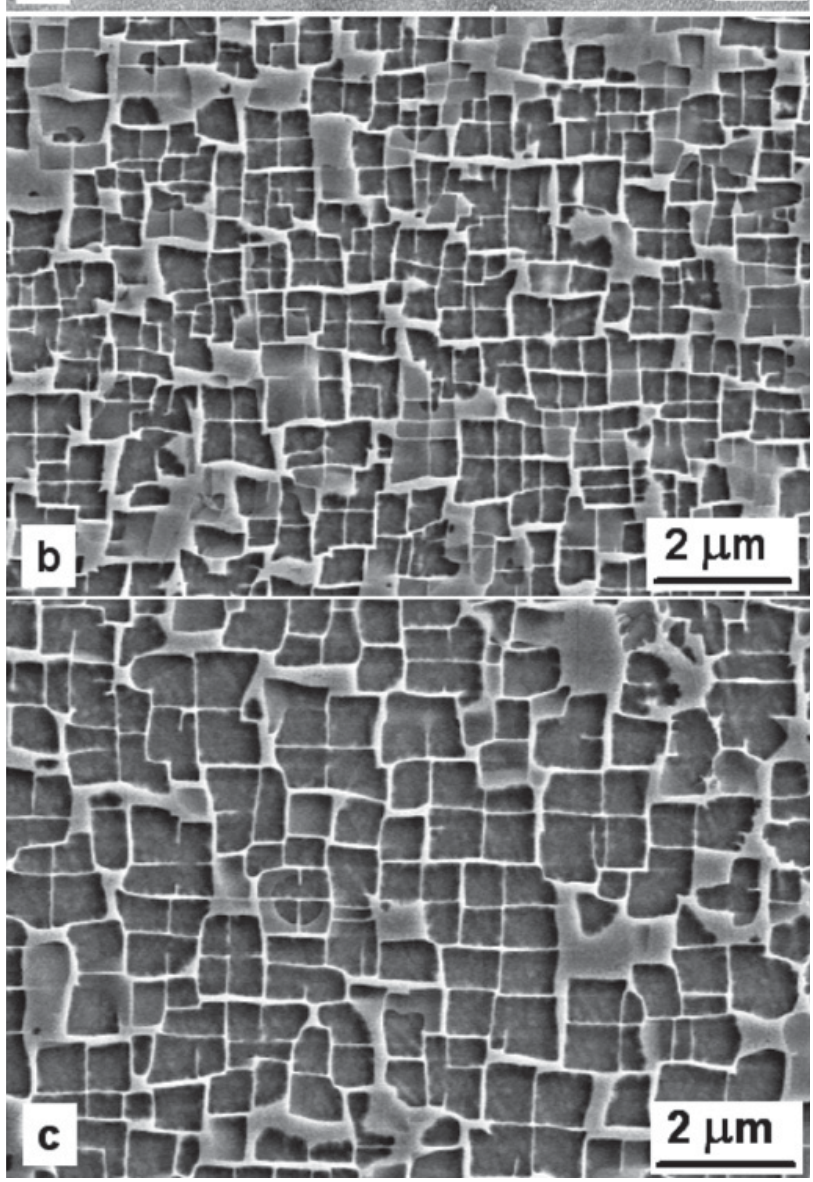

Figure 4. Microstructure of MC-NG after HIP treatment at $1310^{\circ} \mathrm{C}$ for 2 hours under $140 \mathrm{MPa}$, furnace cooled: a) residual $\gamma / \gamma^{\prime}$ eutectic in the interdendritic areas; b) $\gamma^{\prime}$ precipitates in a dendrite core; c) $\gamma^{\prime}$ precipitates in an interdendritic area.

totally eliminate the $\gamma / \gamma^{\prime}$ eutectic. Other tested solutions were to keep a heating rate of $20^{\circ} \mathrm{C} \cdot \mathrm{min}^{-1}$ but choosing a hold time at $1340^{\circ} \mathrm{C}$ of 3 hours (MSHT 5) or 2 hours (MSHT 6). These two modified solution heat treatments lead to complete elimination of the $\gamma / \gamma^{\prime}$ eutectic pools and the last one with a total duration of $3 \mathrm{~h} 30 \mathrm{~min}$ was finally selected as the optimized solutioning procedure (Fig. 3b). Results of porosity measurements performed on a sample solution heat treated according to MSHT 6 are reported 
Table 4. Characteristics of the microporosity for the standard procedure (SP) including a HIP step (see Table 2).

\begin{tabular}{|l|l|l|l|l|}
\hline \multicolumn{2}{|c|}{} & $\begin{array}{l}\mathrm{F}_{A}: \text { area } \\
\text { fraction } \\
(\%)\end{array}$ & $\begin{array}{l}\mathrm{N}_{A}: \\
\text { number of } \\
\text { pores per } \\
\mathrm{mm}^{2}\end{array}$ & $\begin{array}{l}\mathrm{D}: \text { pore } \\
\text { size } \\
(\mu \mathrm{m})\end{array}$ \\
\hline \multirow{4}{*}{ As-cast } & $\max$ & 0.50 & 26 & 27 \\
\cline { 2 - 5 } & average & $\mathbf{0 . 2 8}$ & $\mathbf{1 4}$ & $\mathbf{9}$ \\
\cline { 2 - 5 } & $\min$ & 0.14 & 9 & 3 \\
\hline \multirow{3}{*}{$\mathrm{SP}$} & $\max$ & 0.52 & 15 & 25 \\
\cline { 2 - 5 } & average & $\mathbf{0 . 2 6}$ & $\mathbf{1 0}$ & $\mathbf{1 1}$ \\
\cline { 2 - 5 } & min & 0.10 & 4 & 3 \\
\hline
\end{tabular}

in Table 3. Compared with the SSHT sample, the area fraction and the average size of the pores are slightly lower, while their density is significantly higher. The shorter total duration of the solution heat treatment does not allow the finest pores to coalesce with the largest ones that explains the higher density of pores.

A side effect of the solution heat treatment is partial homogenisation of the chemical dendritic segregations. The level of homogenisation can be a crucial point if the superalloy is prone to precipitation of deleterious topologically close-packed (TCP) phase particles such as $\sigma, \mu, \mathrm{P}$ or Laves phases. These phases precipitate generally within the core of the dendrites where the refractory elements $\mathrm{W}$ and almost Re segregate strongly during the solidification. Indeed these alloying elements participate in the formation of the TCP phases. When applying the 16-hour SSHT solution heat treatment, MC-NG does not show any propensity to form Re-rich TCP phases within the dendrites during hold at high temperatures [5]. The level of dendrite homogenisation is obviously less when applying the MSHT 6 optimized solution heat treatment with a total duration of only $3 \mathrm{~h} 30 \mathrm{~min}$. We have therefore checked if the alloy is still not prone to TCP phase precipitation when solution heat treated using the MSHT 6 procedure. This absence of susceptibility to TCP phase precipitation in MC-NG has been confirmed by performing microstructural assessment on a sample aged for 200 hours at $1050{ }^{\circ} \mathrm{C}$.

\subsection{Optimisation of the HIP procedure}

When applying the SP standard procedure, the HIP process is applied directly on the as-cast material (see Table 2). Microstructural assessment of such HIP'ed samples did not reveal any measurable porosity that evidences the efficiency of this treatment to close the microporosity. However, this HIP treatment at $1310^{\circ} \mathrm{C}$ for 2 hours does not allow to fully dissolve the $\gamma / \gamma^{\prime}$ eutectic pools as illustrated in Fig. 4a. Moreover, SEM microstructural assessments show that the $\gamma^{\prime}$ precipitate sizes are significantly larger in the interdendritic areas than in the dendrites cores due to the residual chemical segregations (Fig. 4b).

The characteristics of the microporosity were determined in a sample been applied the standard solution heat treatment after the HIP process (Table 4). The area fraction of porosity is similar to that measured in the ascast material while the average size of the pores is slightly

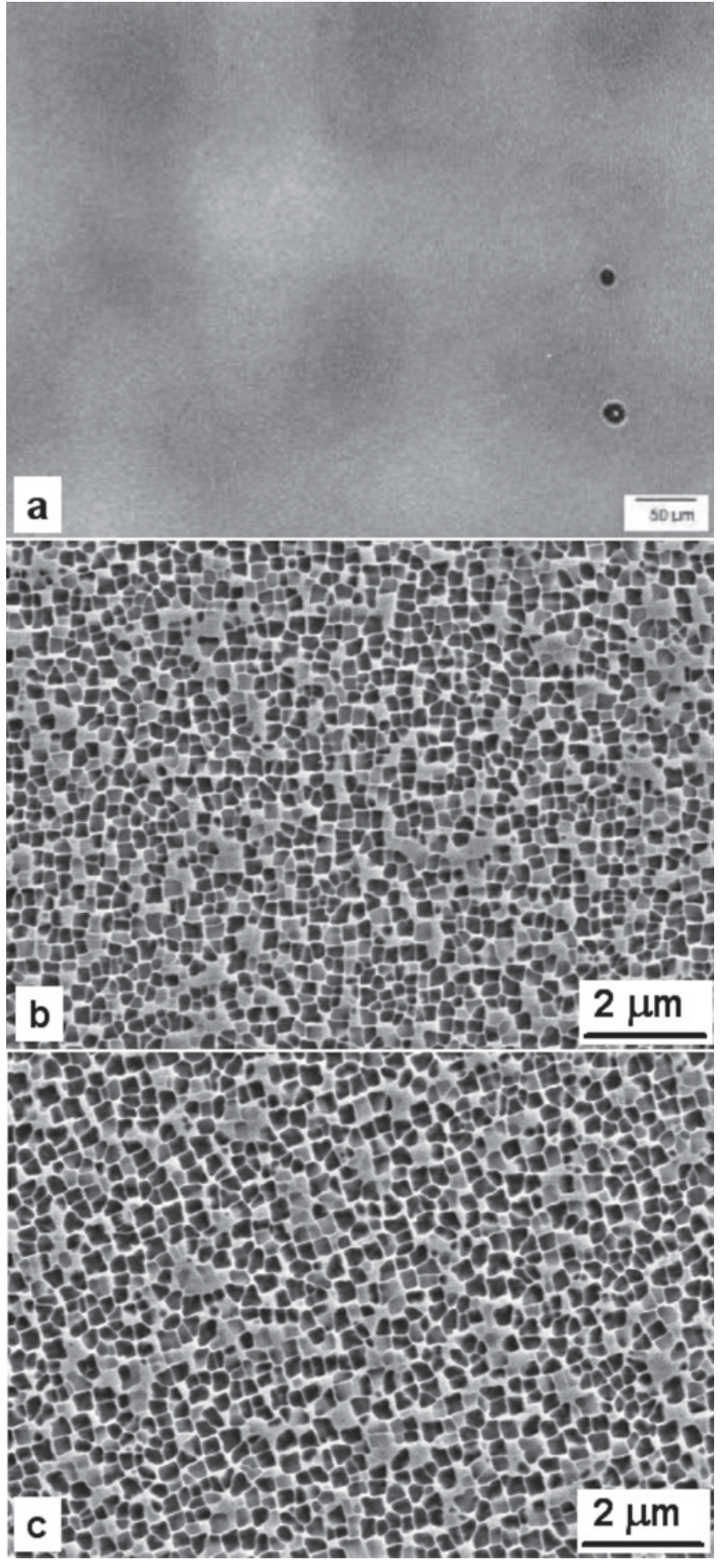

Figure 5. Microstructure of MC-NG after the standard procedure (SP) including a HIP step: a) fully solutionized dendrites; b) $\gamma^{\prime}$ precipitates in a dendrite core; c) $\gamma^{\prime}$ precipitates in an interdendritic area.

higher and their density is smaller. The post-HIP solution heat treatment appears therefore to cancel the beneficial effect of the HIP process. This standard procedure SP allows to fully eliminate the $\gamma / \gamma^{\prime}$ eutectic pools and air quenching results in a satisfying fine distribution of $\gamma^{\prime}$ precipitates, with sizes however always smaller in the dendrite cores than in the interdendritic regions (Fig. 5).

The MP 1 and MP 2 modified procedures have been defined in order to avoid reopening of the porosity likely 


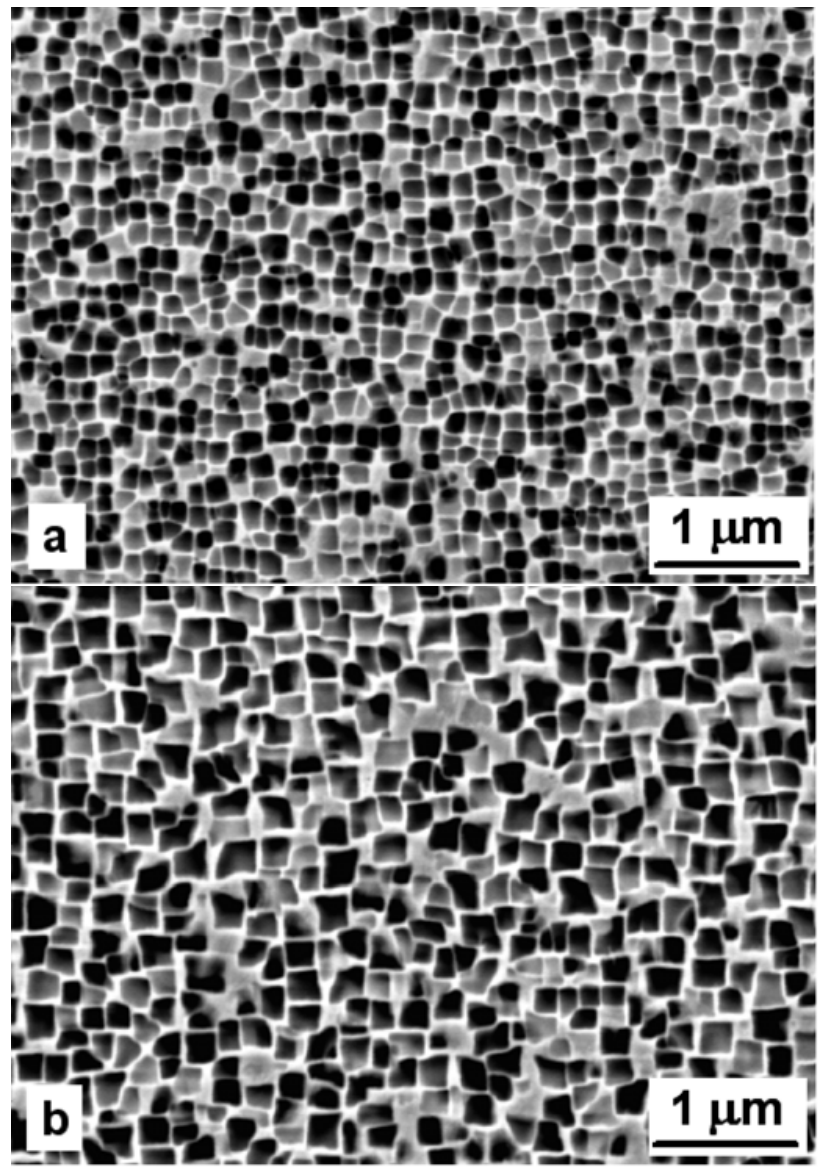

Figure 6. Microstructure of MC-NG after the MP 2 modified procedure including the MSHT 6 optimized solutioning procedure: a) $\gamma^{\prime}$ precipitates in a dendrite core; b) $\gamma^{\prime}$ precipitates in an interdendritic area.

to occur during a long solutioning heat treatment applied after the HIP process. However, a drawback of applying HIP after solutioning is the low furnace cooling rate in the HIP vessel that does not allow to obtain the desired $\gamma^{\prime}$ precipitates size, i.e. less than $0.5 \mu \mathrm{m}$. A short post-HIP solution treatment has therefore been added, followed by rapid air quenching, in order to satisfy the $\gamma^{\prime}$ precipitate size requirement without allowing the porosity to reopen.

Microstructural assessments carried out on samples heat treated according to the MP 1 and MP 2 modified procedures did not reveal any measurable microporosity, that demonstrates the efficiency and the interest of these procedures.
In the samples HIP'ed after having applied the standard or the optimized solutioning heat treatment, the $\gamma / \gamma^{\prime}$ eutectic pools have been totally eliminated. The $\gamma^{\prime}$ precipitates have relatively coarse sizes due to the low cooling rate experienced in the HIP vessel. The subsequent short solution heat treatment for 30 minutes at $1340^{\circ} \mathrm{C}$ with air cooling produces the desired fine $\gamma^{\prime}$ precipitate size as illustrated in Fig. 6 for the sample heat treated by using the MP 2 modified procedure including the MSHT 6 optimized solution heat treatment.

\section{Conclusions}

Testing various solution heat treatments including a HIP step on the MC-NG single crystal superalloy has allowed to identify an optimized procedure in terms of duration and efficiency. Complete solutioning of the $\gamma / \gamma^{\prime}$ eutectic pools and closing of the casting porosity has been obtained by applying a heat treatment sequence including a first solution treatment for $3 \mathrm{~h} 30 \mathrm{~min}$, followed by a HIP treatment for 2 hours and finally by a short postHIP solution treatment for 30 minutes. This particular procedure avoids formation of homogenization pores likely to occur during a long solution heat treatment at high temperature and produces the desired fine size of $\gamma^{\prime}$ precipitates.

The next step of the study will be to perform HCF and LCF test on specimens heat treated according to the optimized procedure in order to check its efficiency in increasing the rupture life under cyclic loading conditions.

This work was partially founded by Snecma under the contract Nr. 920 434088. The authors acknowledge David Firmin for its contribution.

\section{References}

[1] J.J. Jackson, M.J. Donachie, R.J. Henricks, M. Gell, Met. Trans. A, 8A, 1615 (1977)

[2] P. Caron, T. Khan, Advanced Materials and Processes, Vol. 1, H.E. Exner and V. Schumacher, eds., 333 (DGM Informationsgesellschaft, Oberursel, Germany, 1990)

[3] G.L. Erickson, JOM, 47, 4, 36 (1995)

[4] T. Khan, P. Caron, ICAS Proceedings 1986, P. Santini and R. Staufenbiel, eds., 944 (A.I.A.A., New York, USA, 1986)

[5] P. Caron, Superalloys 2000, T.M. Pollock et al., eds., 737 (TMS, Warrendale, PA, USA, 2000)

[6] B.S. Bokstein, A.I. Epishin, T. Link, V.A Esin, A.O. Rodin, I.L. Svetlov, Scripta Mater., 57, 801 (2007) 